\title{
Freud como espectador de Chaplin. La identidad en la diferencia
}

\author{
The Kid | Charles Chaplin | 1921 \\ Juan Jorge Michel Fariña*
}

Universidad de Buenos Aires

Recibido: 7 febrero 2018; aceptado: 5 de marzo 2018

\begin{abstract}
Resumen
En 1920 y 1921 se produjeron dos acontecimientos, uno teórico, el otro estético. Sigmud Freud publicó su escrito Más allá del principio del placer y Charles Chaplin estrenó su film The Kid. Fueron ambas obras de enorme influencia en sus respectivos campos. Este artículo analiza sus puntos de contacto, a propósito de los derechos del niño, el tema de la identidad y la pulsión de muerte. Una vez más el cine se presenta en una función de suplemento de las cuestiones teóricas, permitiéndonos tratar con lucidez temas de actualidad en relación con los niños, niñas y adolescentes.
\end{abstract}

Palabras clave: Pulsión de muerte | Derecho a la identidad | Cine | Psicoanálisis

\section{The Kid}

Dr. en Psicología por la UBA. Profesor Titular Regular Psicología, Ética y Derechos Humanos e Investigador Categoría I Programa UBACyT. CoDirector de Ética y Cine Journal, Aesthethika y JAHR Revista Europea de Bioética. Director del partenariado UBA del Centre d'Études du Vivant, Université Paris VII.

\begin{abstract}
In 1920 and 1921 there were two events, one theoretical, the other aesthetic. Sigmud Freud published his writing Beyond the pleasure principle and Charles Chaplin premiered his film The Kid. They were both works of enormous influence in their respective fields. This article analyzes their points of contact, regarding the rights of the child, the issue of identity and death drive. Once again the cinema is presented as a supplement to the theoretical questions, allowing us to lucidly discuss current issues in relation to children and adolescents.
\end{abstract}

Keywords: Death drive | Right to identity | Cinema | Psychoanalysis

"Él es, indudablemente, un gran artista. Con certeza, siempre representa una única figura: el débil, pobre, indefenso y torpe joven a quien, sin embargo, las cosas terminan saliéndole bien. Pero ¿piensas que en este papel se ha olvidado de su propio ego? Por el contrario, siempre se representa a sí mismo, tal como era en su juventud. No puede alejarse de esas impresiones y, hasta el día de hoy, obtiene para sí mismo la compensación por las frustraciones y humillaciones de ese antiguo período de su vida".

Sigmund Freud, sobre Charles Chaplin, 1931

Distanciados en apenas un año tuvieron lugar dos eventos, uno académico y el otro estético, que vale la pena vincular, ya que ambos contribuyeron a conmover la concepción de la infancia en los albores del siglo XX.
En 1920, Sigmund Freud publica Más allá del principio del placer, obra en la que inaugura los conceptos de compulsión a la repetición y pulsión de muerte, produciendo un giro crucial en su sistema teórico. Inspirado en un inocente juego de su nieto Ernst, que arrojaba y recogía un carretel en ausencia de su madre, Freud introduce allí la referencia al fort da, que iluminaría la noción de juego simbólico, inaugurando una nueva comprensión sobre la niñez y su abordaje analítico.

Un año después, en 1921, Chaplin estrena su película The Kid, que como veremos también significó un hito, y no sólo cinematográfico. Desde entonces, los niños, niñas y adolescentes, como gustamos denominarlos un siglo más tarde, han tenido un protagonismo excluyente en el cine. Este protagonismo ha estado sin embargo

jjmf@psi.uba.ar 
marcado, la mayoría de las veces, por lo que Alain Badiou denominó una concepción ética entendida en su carácter negativo: denunciar la violación a sus derechos, suprimir el espectáculo del mal. ${ }^{1}$ A propósito de la entrega del premio Oscar 2016 a mejor película en lengua no inglesa, decía el filósofo Julio Cabrera:

los norteamericanos premiaron, a lo largo de décadas, muchos filmes extranjeros que contaban historias emocionantes enfocando catástrofes sociales -especialmente el nazismo- envolviendo niños pequeños en situaciones terribles (Fanny y Alexandre, La historia oficial, El ataque, Pelle el conquistador, Viaje de la esperanza, Indochina, Kolya, La vida es bella, Tsotsi). Una buena receta para ganar ese Oscar es, pues, poner niños en situaciones de calamidad, como el pequeño Theeb de la película de Jordania. En ese sentido, el favorito de este año sería El hijo de Saúl, que (como El tambor, El ataque y La vida es bella) juntan nazismo con infancia infeliz.

Ante este argumento incontrastable, la pregunta es evidente ¿existe una vía posible para salir de semejante atolladero? ¿Es posible pensar la infancia en el cine sin sucumbir a esa lógica? Nuestro método será revisitar aquella obra pionera de Chaplin proponiendo una lectura de los estragos en la infancia, que no quede anclada en la denuncia del "espectáculo del mal”. Una lectura que nos permita sentar en cambio las bases para una ética de la afirmación del sujeto.

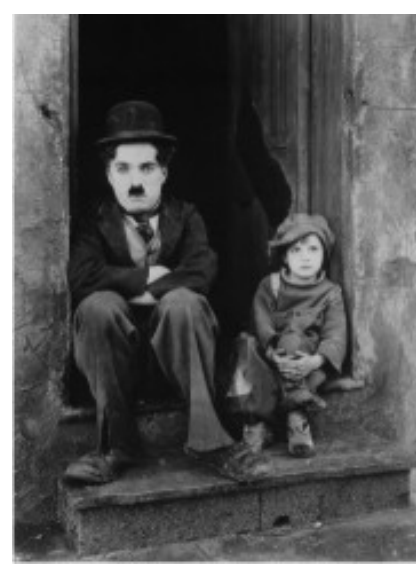

El argumento del film The Kid, ideado por el propio Chaplin, es relativamente sencillo, pero de una enorme profundidad. Una mujer joven da a luz a un hijo no deseado y con profundo dolor decide dejarlo en un hogar acomodado. Pero las circunstancias hacen que el bebé termine abandonado en un barrio marginal donde es azarosamente encontrado por el vagabundo interpretado por Charlie Chaplin. La primera reacción de este hombre es deshacerse del niño, pero poco a poco se deja afectar por el vínculo y finalmente decide adoptarlo y asumir su crianza. La historia continúa, el niño cumple cinco años, y es allí cuando nos interesa tomar dos escenas que tendrán importancia analítica. La primera es la del momento en que la asistencia pública pretende llevarse al niño a un orfanato, argumentando la precaria condición económica de su padre adoptivo. La escena es desgarradora, porque el niño expresa su deseo de permanecer junto al padre, quien ha cumplido cabalmente su función. Pero estamos en 1921 y los derechos de niños niñas y adolescentes no estaban todavía en el horizonte de la humanidad. Es sin embargo el cine quien nos sensibiliza sobre el tema, adelantándose en casi un siglo a la legislación contemporánea. Volveremos sobre la cuestión.

La otra escena, inmediatamente anterior en la trama y decididamente clave para nosotros, es el momento en que el médico interroga al vagabundo respecto de si él es el padre del niño. Recordemos que este hombre lo recogió de la calle, asumió su crianza, convivió con él durante cinco años y lo ama profundamente, como el niño a él. Sin embargo, no saca ventaja de ello y responde de manera honesta con una bella fórmula "prácticamente... sî", y ante el pedido de explicaciones del médico, le muestra la breve nota que llevaba el niño entre sus ropas cuando lo encontró: "por favor hágase cargo de este niño huérfano". Y será esa nota, escrita de puño y letra por su madre, la que le permita luego a ella reconocer al niño como propio y remontar la historia de abandono.

Van siendo introducidos así los detalles clínicos de la trama. Esta secuencia, que muestra a un padre adoptivo guardando amorosamente la nota manuscrita que dejó su madre, tiene su reverso ominoso en la escena en la que el padre biológico del niño deja que el fuego consuma la fotografía de la madre del niño, desentendiéndose así de su responsabilidad en la historia. Este hallazgo de Chaplin, de una letra que permanece y otra que se consume, introduce la cuestión del significante en la batalla por la identidad. Es allí cuando el film hace interlocución con los descubrimientos freudianos.

Porque en The Kid la trama está organizada para contradecir un supuesto orden "natural" de las cosas. La Maternidad Pública expulsa a una madre con su bebé recién nacido; lo hace con un gesto despreciativo y condenatorio por su condición de madre soltera. La madre a su vez, atormentada por el estigma, abandona luego al hijo. El niño queda en un callejón que resulta ser el basural del vecindario, al que arrojan desperdicios desde los departamentos altos. De hecho, el bebé es encontrado por el vagabundo, que busca entre los desechos colillas de cigarrillos... Pero todo el film está allí para indicarnos que es contra esta adversidad que se crea la vida. No la vida or- 
denada y homeostática -que resulta no existir finalmente- sino la otra que se inventa a partir de la falla estructural en la primera. La pulsión de muerte se instala allí.

Recordemos que "pulsión de muerte" es el nombre freudiano que paradójicamente designa su opuesto: un exceso de vida, un impulso que persiste más allá del ciclo biológico. En su seminario sobre la ética del psicoanálisis, Lacan (1992 [1959-60]) retoma esta vertiente del concepto cuando dice

Si todo lo que es inmanente o implícito en la cadena de los acontecimientos naturales puede ser sometido a una pulsión llamada de muerte, esto es así sólo en la medida en que hay cadena significante. Es exigible, en efecto, que aquello de lo que se trata sea articulado como pulsión de destrucción, en la medida en que pone en duda todo lo que existe. Pero ella es igualmente voluntad de creación, voluntad de recomienzo (p. 257).

La actitud del personal de la maternidad pública, la iniciativa temeraria de la madre, el desinterés inicial del vagabundo, están allí para introducir situaciones gozosas en que los personajes parecen realizar la paradoja kantiana: estar bien en el mal. ${ }^{2}$ Pero habrá un elemento que se sustraiga a esa serie. Se trata del deseo, que se abre camino introduciendo una dimensión ética. Ante todo, el deseo no sabido de esa madre que deja cifrada en una carta la marca de su cuerpo, abriendo con su grafía una oportunidad a la cadena filiatoria, cadena que no sigue la vía de la biología sino la del significante. También por cierto en el vagabundo, cuyas conductas se presentan bajo una moralidad francamente objetable: cuando considera deshacerse de la criatura por los medios más abyectos, o cuando educa al niño en actos delictivos para medrar con ello. ¿Dónde se juega entonces el deseo como instancia ética? Justamente en la función paterna que se sobrepone a las miserias del personaje. Y en particular, en el deseo de filiar.

Ello nos sitúa en el problema de la "identidad". La pulsión de muerte evoca precisamente la nostalgia de un estado anterior a la aparición de la individualidad y de la diferenciación sexual. Un estado en el que vivíamos antes de convertirnos en mortales y de distinguirnos unos de otros. Si lo idéntico es la propiedad de los organismos unicelulares, el gran logro de la humanidad es saber vivir (y morir) en la complejidad y la diferencia. En las antípodas, un cáncer es una célula que ba olvidado cómo morir (Baudrillard, 2010).

Para los humanos, para el parlêtre, según el bello neologismo con el que Lacan hace su relevo del inconsciente freudiano, la muerte deviene una instancia vital. Y la identidad su correlato de conquista significante que se sostiene en la diferencia.
Por eso The Kid está pleno de escenas lúdicas -el juego con los panqueques, la graciosa alternancia con la tetera-mamadera- en las que el vagabundo improvisa la relación con ese hijo que lo inventa a sí mismo como padre. Y el necesario final abierto de la trama resulta así otro acierto del guión: como en tantas historias sobre la filiación tampoco ha llegado en esta el momento de concluir.

A manera de epílogo, propondremos en cambio la fugaz interlocución con otro film: Benjamin Button. Muy cerca del estreno de The Kid y de la escritura del texto de Freud, en 1918, año en que finaliza la Primera Guerra Mundial, nace un extraño bebé. Su madre muere en el parto y encomienda el cuidado del niño a su esposo, quien se horroriza por el espectáculo de ese niño infinitamente arrugado, y lo abandona a su suerte. Pero el bebé sobrevivirá y será bautizado Benjamín por una mujer que decide adoptarlo. Y como sabemos, vivirá como viejo y luego irá enjuveneciendo. Ya maduro, el padre de Benjamín se acerca a su hijo. Lo hace por piedad, sumido en la culpa por haberlo abandonado y sorprendido por su inesperada supervivencia. No sospecha siquiera qué es lo que en realidad va a buscar en ese encuentro. No sabe aún que el horizonte de la conversación no es la muerte que lo angustia, sino la vida que todavía puede ser vivida plena de ilusión, en el sentido que le da Freud al término en El porvenir de una ilusión, es decir de ficción. Entonces, cuando ese padre esté dispuesto a serlo, Benjamin lo acompañará en una mutua adopción que haga del despojo, acto. A ese padre, que lo privó del apellido, de la infancia, de la memoria de su madre, a ese padre Benjamín terminará aceptándolo, haciendo suya la filiación que se le ofrece. El padre lo abandonó al nacer, el hijo lo acompañará al morir. ${ }^{3}$

Las películas también terminan, nos abandonan, pero nos dejan con la secreta lucidez del porvenir. Son estas lecturas singulares las que hacen que un acontecimiento pueda constituirse en motor de una verdad. Están ligadas a la particularidad de una situación pero sólo por el sesgo de su vacío. No estamos ya frente a una concepción "negativa” de la ética, a una ética de la opinión consensuada que se define por oposición al Mal, sino a la que, haciendo acontecimiento, emerge como una verdad impensada del sujeto.

Por lo mismo esta verdad no alcanzará nunca potencia completa, total. Porque el sujeto resultante del proceso de una verdad no tiene poder alguno de nominación sobre todos los elementos de la situación. Pero puede, gracias a la magia del cine y la potencia de un análisis, volver a jugar el juego, introducir el tiempo lógico, organizar algunos retazos de historia e inventarse en ella. 


\section{Referencias}

Baudrillard, G. (2010). La ilusión vital. Buenos Aires: Siglo XXI.

Cabrera, J. (sin fecha) “El abrazo del Oscar”. Recuperado de https://lacuevadechauvet.com/2016/02/27/el-abrazo-del-oscar/ Lacan, J. (1992 [1959-60]) El Seminario, Libro 7: La ética del psicoanálisis, Buenos Aires: Editorial Paidós.

1 Esta tesis de Alain Badiou se encuentra desarrollada en distintas conferencias dictadas por el filósofo francés, entre ellas "Ética y Psiquiatría”, pero fundamentalmente en su obra "La ética: Ensayo sobre la conciencia del mal”. Revista Acontecimiento, número 8, 1994.

2 Para un tratamiento de esta cuestión ver el reciente libro de Eduardo Laso "Ética y malestar. Ensayos sobre ética psicoanalítica". Ediciones Rojo, Buenos Aires, 2016.

3 Para un desarrollo más extenso sobre este film, ver nuestro texto "Lo que el cine nos enseña sobre la vejez". En Michel Fariña, J. y Solbakk, J.H. Bioética y cine: Tragedia griega y acontecimiento del cuerpo. Letra Viva, Buenos Aires, 2012. 